\title{
Velocities of the Smith Glacier ice tongue and Dotson Ice Shelf, Walgreen Coast, Marie Byrd Land, West Antarctica
}

\author{
B. K. Lucchitta, K. F. Mulins, G. E. Smith, \\ U.S. Geological Survey, Flagstaf, AZ 86001, U.S.A. \\ J. G. Ferkigno \\ U.S. Geological Survey, National Center, Reston, VA 22092, U.S.A.
}

\begin{abstract}
ABS'IRACII. Velocity measurements were made for two time intervals on the Smith Glacier ice tongue (1973-88 and 1988-90) and three on the Dotson Ice Shelf (1972-88, 1973-88 and 1988-90). The Smith Glacier ice tongue velocities for the two intervals are similar near the grounding line but show a progressive increase toward the terminus in the late $1980 \mathrm{~s}$. The Dotson Ice Shelf velocitics remained virtually constant during all three time intervals. The increased velocities of the Smith Glacier ice tongue may be attributed to a general loss of densely packed icebergs that buttressed the terminus during the $1970 \mathrm{~s}$ but drifted out to sea during the late $1980 \mathrm{~s}$. The Smith Glacier ice tongue receded as much as $10 \mathrm{~km}$ between 1973 and 1988 , the Dotson Ice Shelf $5-7 \mathrm{~km}$ in the same time period. Similar observations of drifting and calving were made for the adjacent 'Thwaites Glacier icc tongue. The cause of the loss of ice in the region is unknown but it may have been a change in winds or a warming of the air or water during the late 1980s.
\end{abstract}

\section{INTRODUCTION}

The ice streams draining the West Antarctic ice sheet into the Ross and Ronne Ice Shelves have been studied intensively, but relatively little is known about the ice streams and glaciers draining the ice sheet through the Marie Byrd Iand coast. The most conspicuous ice streams in that area are Pine Island and Thwaites Glaciers, which lack a buttressing ice shelf at their termini. They have been studied by Hughes (1981), Crabtree and Doake (1982), Lindstrom and Hughes (1984), Lindstrom and Tyler (1984) and Ferrigno and others (1993), but little is known about the glaciers and ice shelves west of Thwaites Glacicr along the Marie Byrd Land coast. The present study concerns velocities on ice tongues and ice shelves in that area (Fig. 1). It is part of a more comprehensive mapping project and inventory of all glaciological features along the Marie Byrd Land coast and of changes that have occurred there within the last 20 years. Here, we present velocities obtained for Smith Glacier, which empties into an icc-shclfless part of the Amundsen Sea immediatcly west of Thwaites Glacier, and for the Dotson Ice Shelf at the mouth of Kohler and Horrall Glaciers on the Walgreen Coast (U.S. Gcological Survey, 1968).

\section{METHOD}

Large crevasses in the floating part of glaciers or ice shelves commonly retain their identity over many years and, by measuring their displacement on sequential satcllite images, their average velocities for a given time interval can be determined. For our measurements, we digitally co-register the images by using a minimum of three well-dispersed fixed points such as nunataks or ice

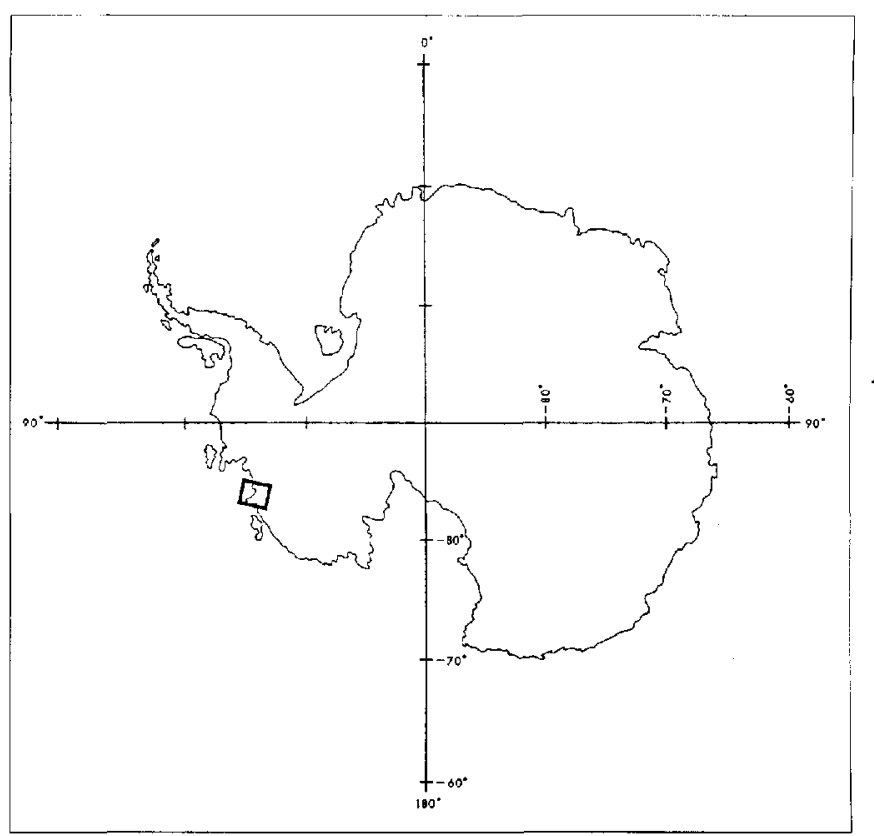

Fig. 1. Index map of investigated area in Marie Byrd Land, Antarctica. 
Table 1. Landsat images used in this study

Image $I D^{*}$

\section{Date Approximate Type of acquired original ground image resolution}

Landsat 1

$1160-14554$ (MSS) 30 Dec $1972 \quad 80$

CC' I

Landsat 1

80

CCT

Landsat 4

41996-14580 (TM) 2 Jan 1988

Landsal 4

42748-15073 (TM) 23 Jan 1990
1177-14500 (MSS) 16 Jan 1973

walls. We then use an interactive-display technique to match and align the crevasse patterns displaced with time, and we calculate the velocities from the distances moved. To obtain the distribution of average velocities over the length of the glacier tongues, we also measure the distance from the location of each point on the earlier image of a pair to a base line drawn perpendicular to glacier movement and ideally lying on the grounding linc; where the grounding line is complex, the base line may only approximate its position. Because the velocity field may also change across the glacier tongues, we divide them into several segments (identified by upper-case letters on our images), and wc subdivide the segments into longitudinal paths (identified by $\mathrm{P} 1, \mathrm{P} 2$, etc.). To obtain an estimate of the spread of measured points, we calculate a regression line and the mean absolute deviation of the points about this line. The measurement results are shown in graphs that display average velocities per given time interval versus the distance from the base line for all points in each field. To give an indication of the gencral velocity of an ice tongue or ice shelf, we also calculate the mean of all the average velocity values per path and per segment, and we give the results in tables.

* MSS, Multispectral Scanner; TM, Thematic Mapper.

† Image that served as base for co-registration. Scanned image, $50 \mathrm{~m}$ pixel $^{-1}$ resolution, scalc 1:1003200.

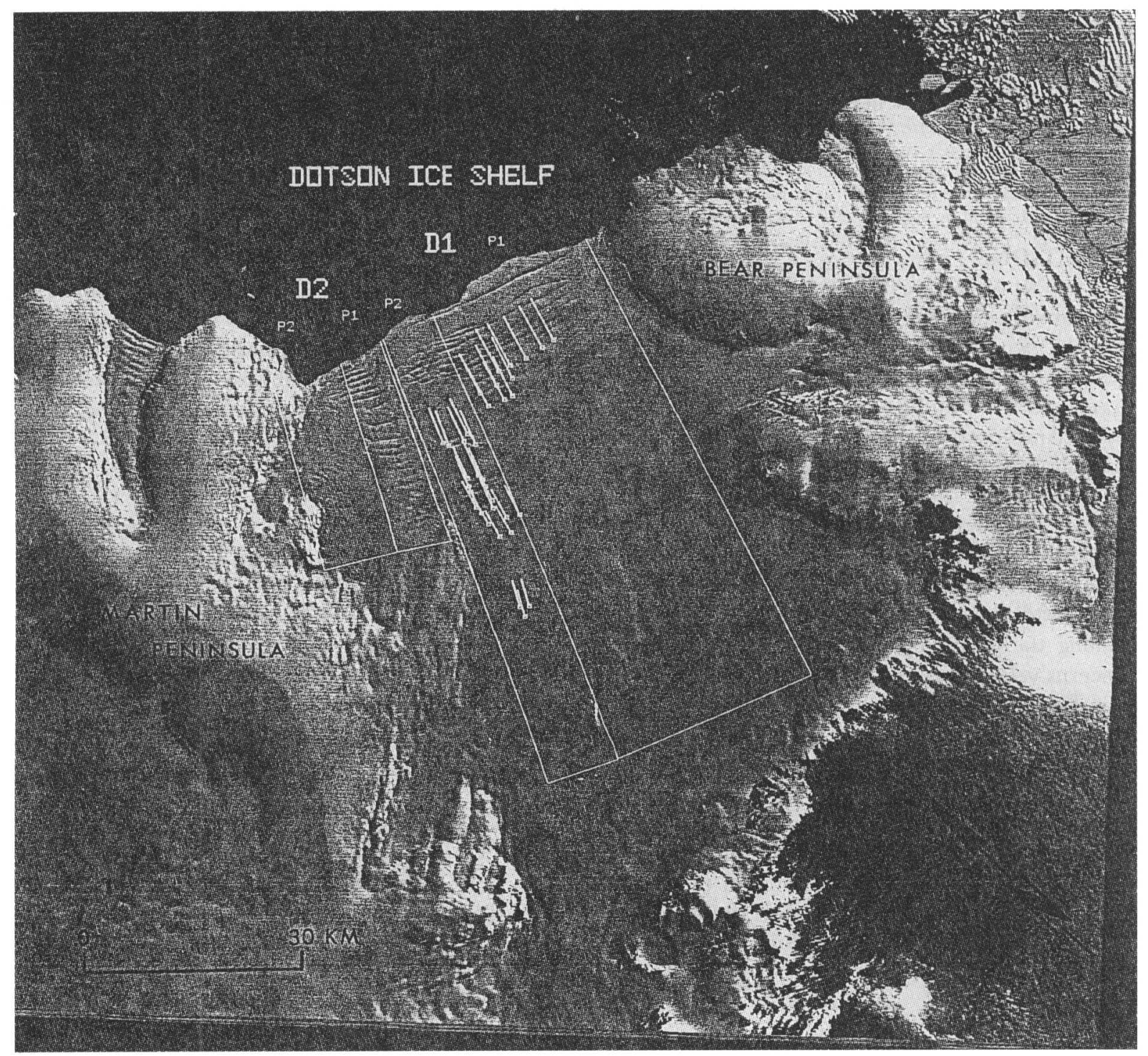

Fig. 2. Dotson Ice Shelf and displacemenl veclors of its crezasse patterns and distances moved during 15.0year interval (December 1972-January 1988). Landsat 1 MSS image 1160-14554, 30 December 1972. 


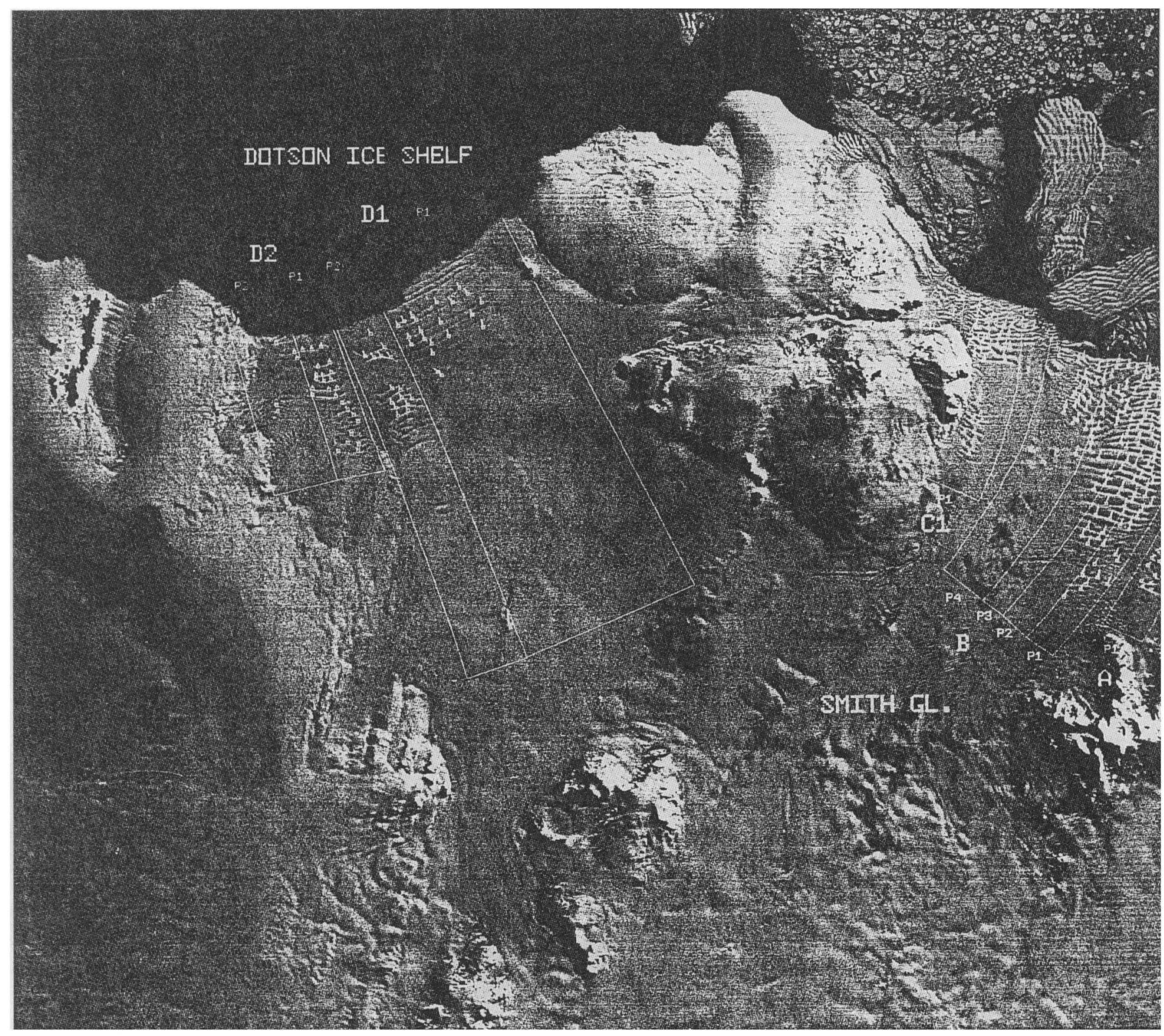

Fig. 3. Dotson Ice Shelf, Smith Glacier and displacement vectors of their crevasse patterns and distances moved during 15.0 year interval (January 1973 Jamuary 1988). Landsat 1 MSS image 1177-14500, 16 January 1973. Orientation, scale and feature names as in Figure 2.

Dctails of our method have been described by Lucchitta and others (1993).

In this study, the velocities were measured on four corcgistered Landsat images (Table 1). The Multispectral Scanner (MSS) images were obtained from Computer Compatible Tapes (CCTs), and the Thematic Mapper TM images from scanned transparencies becausc of the high cost of Landsat (TM) computer tapes. For the present study, we co-registered three of the images to the scanned 1988 I.andsat 4 Thematic Mapper (TM) image, Thus, we were able to obtain average velocities for the time intervals 1972-88 (Fig. 2), 1973-88 (Fig. 3) and 1988-90 (Fig. 4).

Our previous investigations (Lucchitta and others, 1993 ) have shown that crrors in measured avcragc velocities may be as little as $0.02 \mathrm{~km}_{\text {year }}{ }^{1}$ if (1) the time interval is longer than 10 ycars, (2) the average velocity is higher than $0.5 \mathrm{~km}$ year ', (3) co-registration points arc well dispersed and surround the ice tongue to be measured, and (4) the image pair includes a Landsat 4 or 5 image. Iandsat TM images are accurate to sub-pixel levels, thus meeting National Horizontal Map Accuracy standards for scales as large as 1:100000 (Borgeson and others, 1985; Welch and others, 1985). For this study, we used the same TM image as a base for co-registration; therefore, all the measurements were made at the same scale. The earlier time intervals (1972-88 and 1973-88) exceed 10 years; most average velocities approach or exceed $0.5 \mathrm{~km}$ year $^{-1}$; at least eight well-dispersed coregistration points werc used to match the images and they were co-registered to a Landsat 4 TM image. The time interval of 1988-90 is much shorter but both images are of the higher resolution of Landsat TM. For our situation, we predict the measurements are accurate to about $0.05 \mathrm{~km}$ ycar $^{-1}$.

We also investigated the residual pixel errors remaining after co-registering the 1973 MSS to the $1988 \mathrm{TM}$ image, because internal distortions causing possibly 


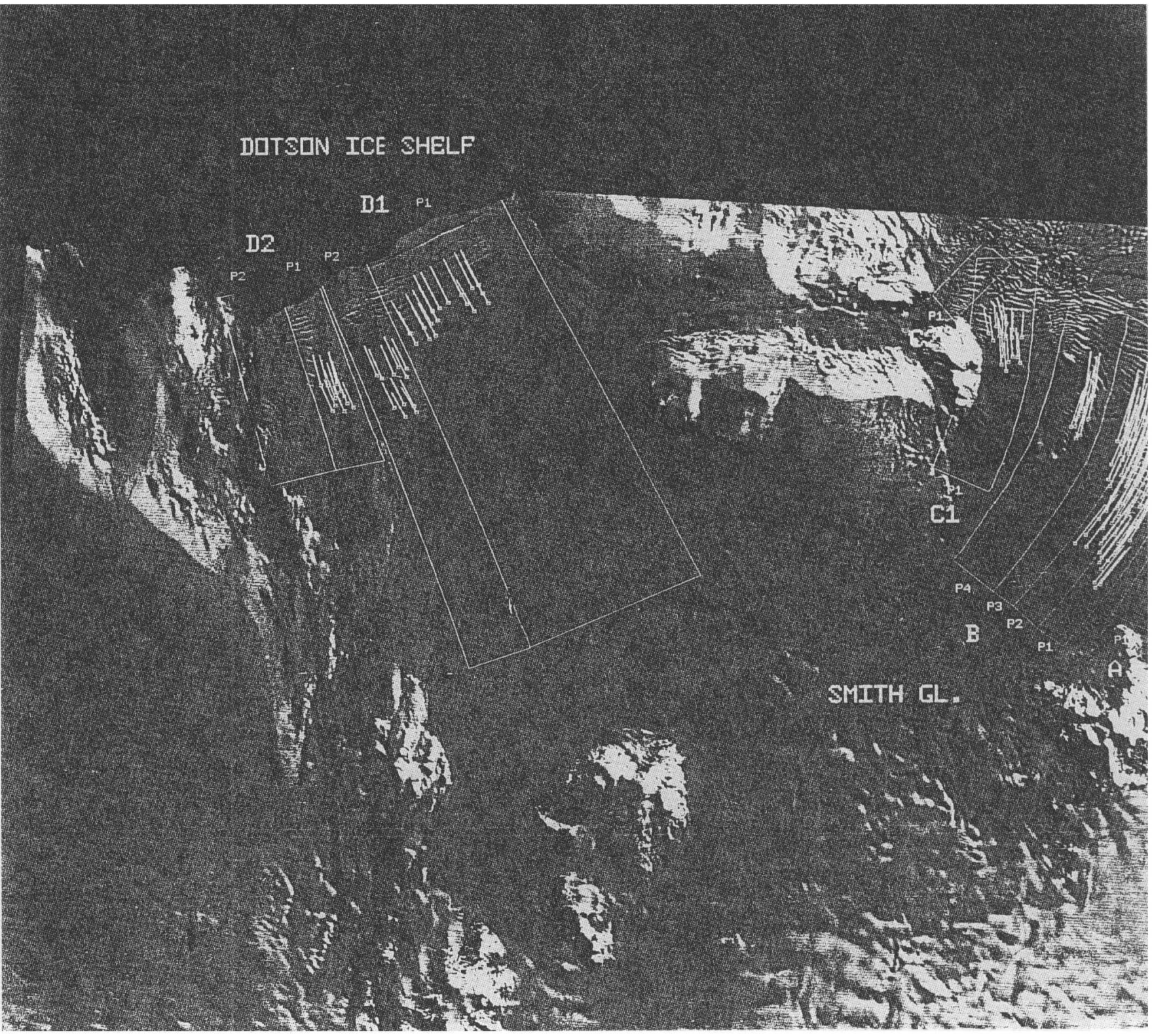

Fig. 4. Dotson Ice Shelf, Smith Glacier and displacement vectors of their crevasse patterns and distances moved during 2.1 year interval (January 1988-January 1990). Landsat 4 TM image 41996-14580, 2 January 1988. Orientation, scale and feature names as in Figure 2.

substantial errors were introduced in the Iandsat 1,2 and 3 MSS images due to variations in scanning-mirror velocity and roll, pitch and yaw of the spacecraft. Gencrally, to minimize errors, we use only co-registration points with residual errors that are less than two pixels, or $100 \mathrm{~m}$ on the ground at the approximate 1 : 1000000 scale of the images. After co-registering our images, we measured the residual crrors of 36 randomly selected points dispersed across the images and found the errors are no more than one pixel or an average of $<0.25$ pixcls ( $<15 \mathrm{~m}$ on the ground).

Misidentification of crevasse patterns remains another potential source for error. The greater the scatter in our plots of velocitics versus distance to the base line, the more likely it is that measurement errors occurred. Also, shorter time intervals generally cause greater scatter, because even slight imprecisions in measurement are proportionately more noticeable over short times. Our calculated mean absolute deviation about the regression line gives an indication of measurement errors; however, locally the spread about the regression line may reflect real velocity variations across the width of the ice tongue or ice shelf rather than errors. We used two mean deviations about the regression line to climinate points of obvious faulty measurements from our statistics.

\section{RESULTS}

\section{Smith Glacier}

Smith Glacier empties into the Amundsen Sea immediately west of the 'Thwaites Glacier ice tongue (Fig. 1). The Smith and Thwaites Glacicr ice tongues appcar to be remnants of a former ice shelf that extended from Bear Peninsula in the west toward Pinc Island Bay in the east (U.S. Gcological Survcy, 1968). Smith Glacier drains a major part of the West Antarctic ice sheet (Swithinbank, 

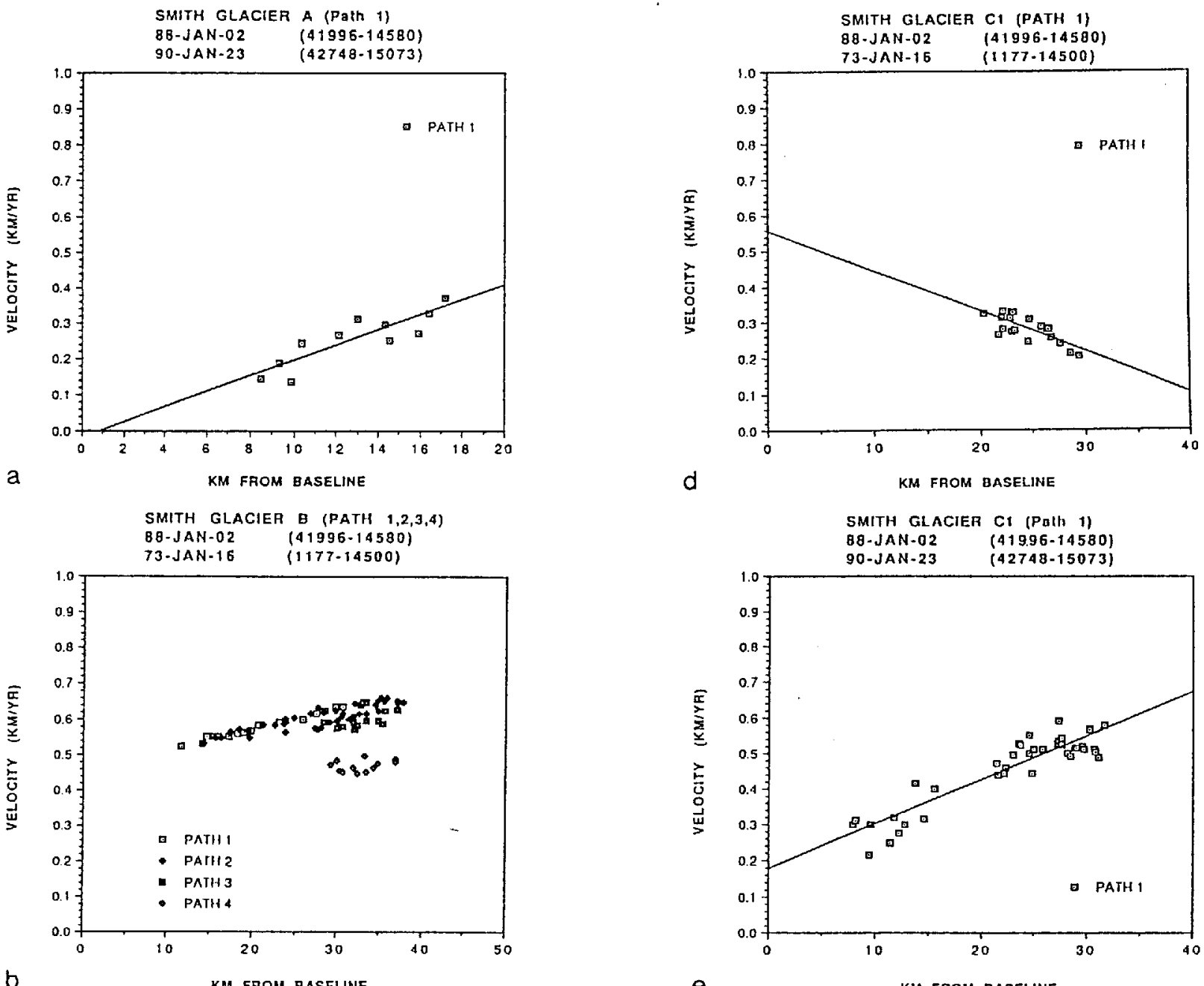

b

KM FROM BASELINE

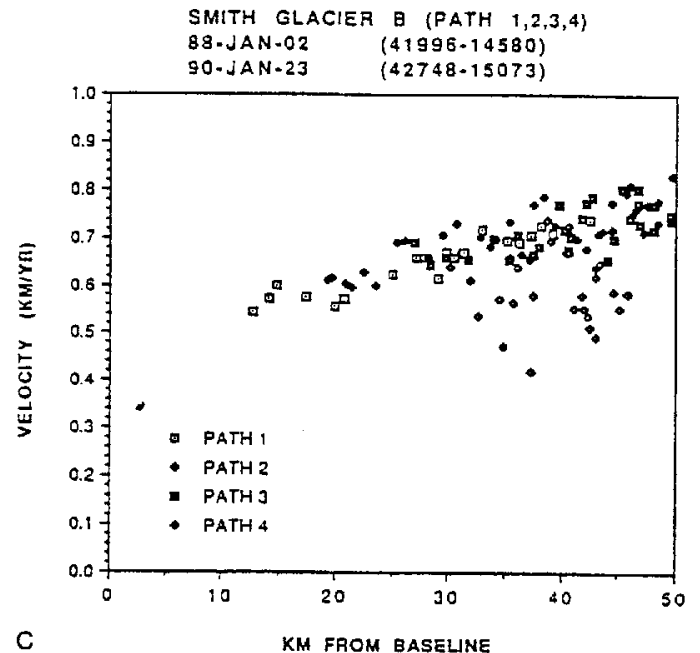

e

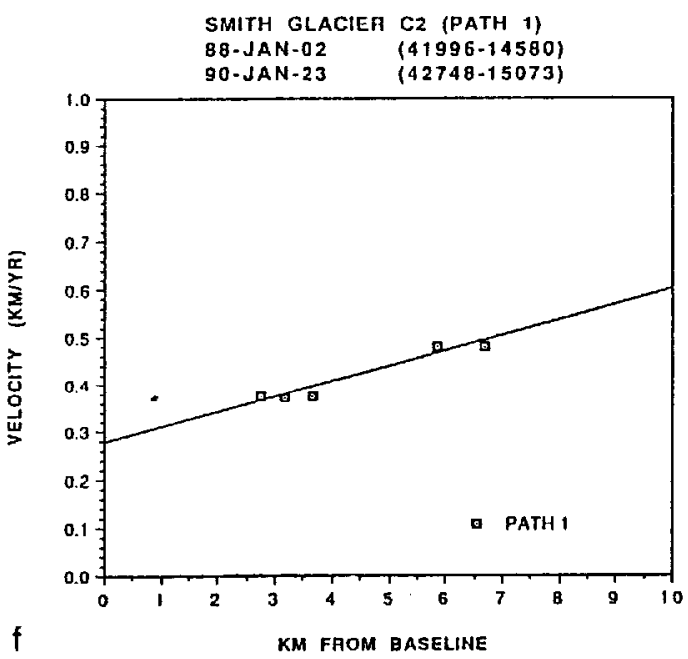

Fig. 5. Average annual velocity of Smith Glacier plotted against distance to base line. a. 2.1 year interval, 1988-90;b. 15.0year interval, 1973-88; c. 2.1 year interval, 1988-90; d. 15.0year interval, 1973-88; e. 2.1 year interval, 1988-90; $f$. 2.1 year interval, 1988-90 (note change in scale).

1988) between Mount Takahe and the Executive Committee Range. Bedrock in the Smith Glacier and Dotson Ice Shelf region lies near $500 \mathrm{~m}$ (Drewry, 1983).

We subdivided the Smith Glacier ice tongue into four segments with one to four paths per segment (Figs 3 and 4). Displacement of crevasse patterns on the Smith Glacier ice tongue was measured for two time intervals (1973-88 and 1988 90). The velocity of path 1 of segment
Smith A (Figs 4 and 5a; Table 2) was slightly higher than vclocities on other icc shclves (Lucchitta and others, 1993). This path is not part of the main glacier ice tongue and has a very small intake area. Segment Smith B covers the main part of the ice tongue (Figs 3 and 4). Paths 1-3 were relatively fast; path 4 was slowed by several small ice rises in its path (Fig. 5b and c; Table 2). Comparison of the graphs (Fig. 5b and c) and of the general velocity 
Table 2. Average velocities

2,7 an $1988-2.3$. 7an 1990

Interval: $753 d$ (2.1 years)
16 . Jan 1973-2 Jan 1988

Interval: 5464 d (15.0years)
30 Dec $1972-2$ fan 1988

Interval: $5482 d$ (15.0years)

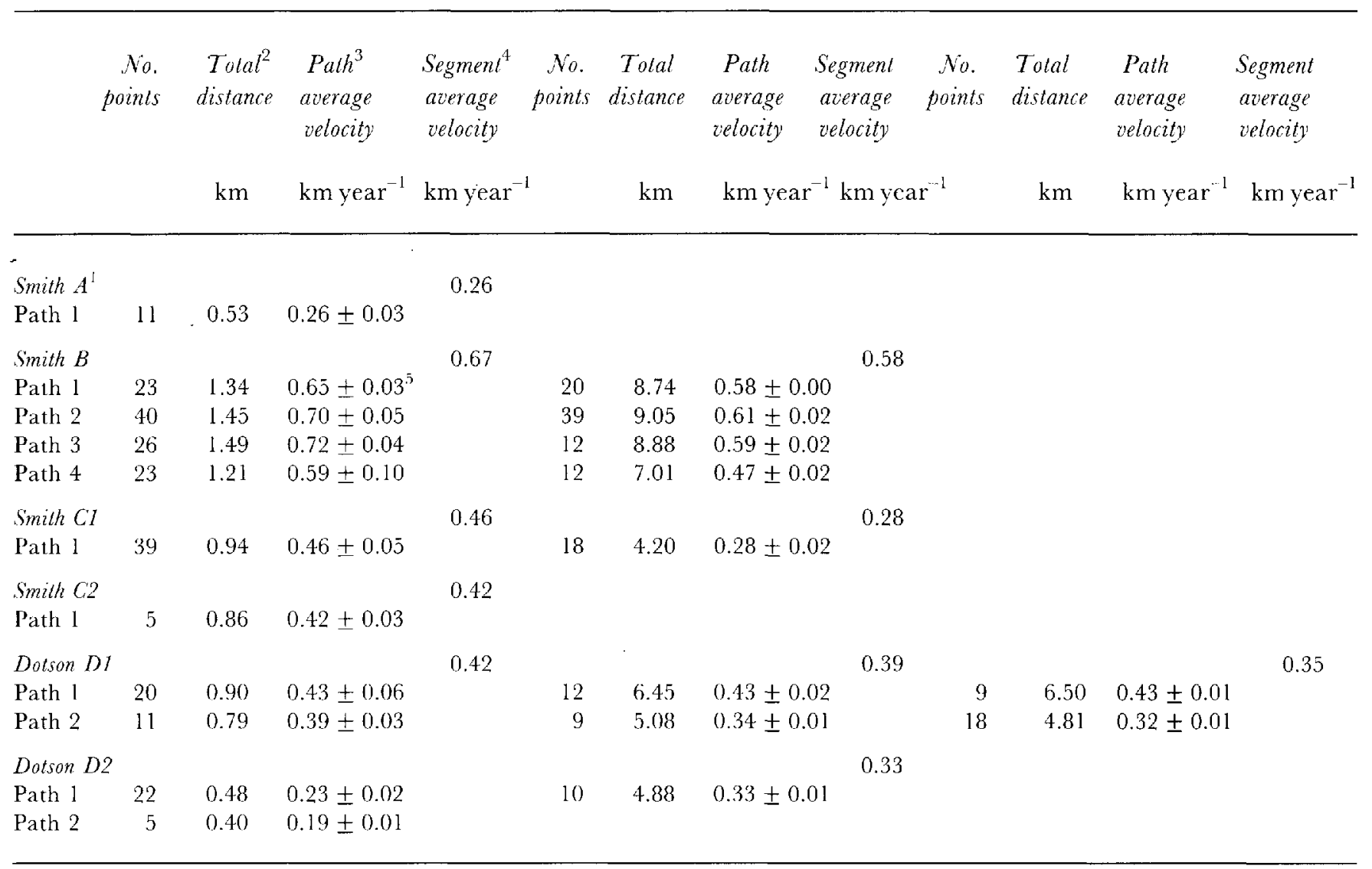

${ }^{1} \mathrm{~A}, \mathrm{~B}, \mathrm{C1}, \mathrm{C} 2, \mathrm{D} 1$ and D2 represent segments of the ice tongues as shown in Figures 2, 3 and 4.

${ }^{2} \Lambda$ verage total distance per path (see Figures 2, 3 and 4) traveled in given time interval.

${ }^{3}$ Average velocity per path in given time interval. (Note that average may cover different sections along length of ice tongue for different time intervals.)

${ }^{4}$ Average velocity of all points in all paths within segment in given time interval.

${ }^{5}$ Mean absolute deviation of the points about the regression linc.

values (Table 2) shows an increase in velocity of about $0.1 \mathrm{~km} \mathrm{year}^{-1}$ for the $1988-90$ time interval.

Path 1 of Smith Cl (Figs 3, 4, 5d and e; Table 2) has a negative slope on the graph representing 1973-88 Fig. 5d). This apparent decrease in velocitics toward the calving front can be readily explained: the proximal measurements were made in a faster part of the ice tongue near the main glacier, and the distal measurements include points in a slower part of the tongue near the shear zone with the adjacent Bear Peninsula (Fig. 3). Smith $\mathrm{C} 1$ is slower than Smith B, because the Cl segment is impeded by the basc of Bear Pcninsula (Figs 3 and 4). The $1988-90$ average velocities are about $0.15 \mathrm{~km}$ year ${ }^{1}$ higher than the 1973-88 velocities, despite a cluster of low velocities measured in a shear zone next to the peninsula and included in the averages (Figs 4 and 5e; Table 2). The 1990 image contains some cloud cover in this area; the partial obscuration could causc errors in our measurements due to misidentification of crevasse features on this imagc. However, the systematic trend in velocities derived from the 1988-90 image set (Fig. 5e), along with a careful check of the features in our initial data collection, make this possibility less likely. Also, the later measurements were made closer to the calving front, which had receded between 1973 and 1988; the different position of the front may explain the higher velocities of the later time interval.

Path 1 of Smith C2 (Figs 4 and 5f; Table 2) was measured only for the 1988-90 time interval. It is on a short ice tongue between ice rises of Bear Peninsulit, and its relatively high velocity probably reflects the break-up of the ice tongue near the terminus; this velocity is similar to those near the terminus of Smith C1 (1988-90). It is possible, though unlikely, that these measurements may also be in error because of the poor viewing conditions.

\section{Dotson Ice Shelf}

The Dotson Ice Shelf is partly fed by branches of Smith Glacier (U.S. Geological Survey, 1968). The feeders cross a low swell to form the eastern part of the ice shelf and they spill through a gap in the Kohler Range to form the 

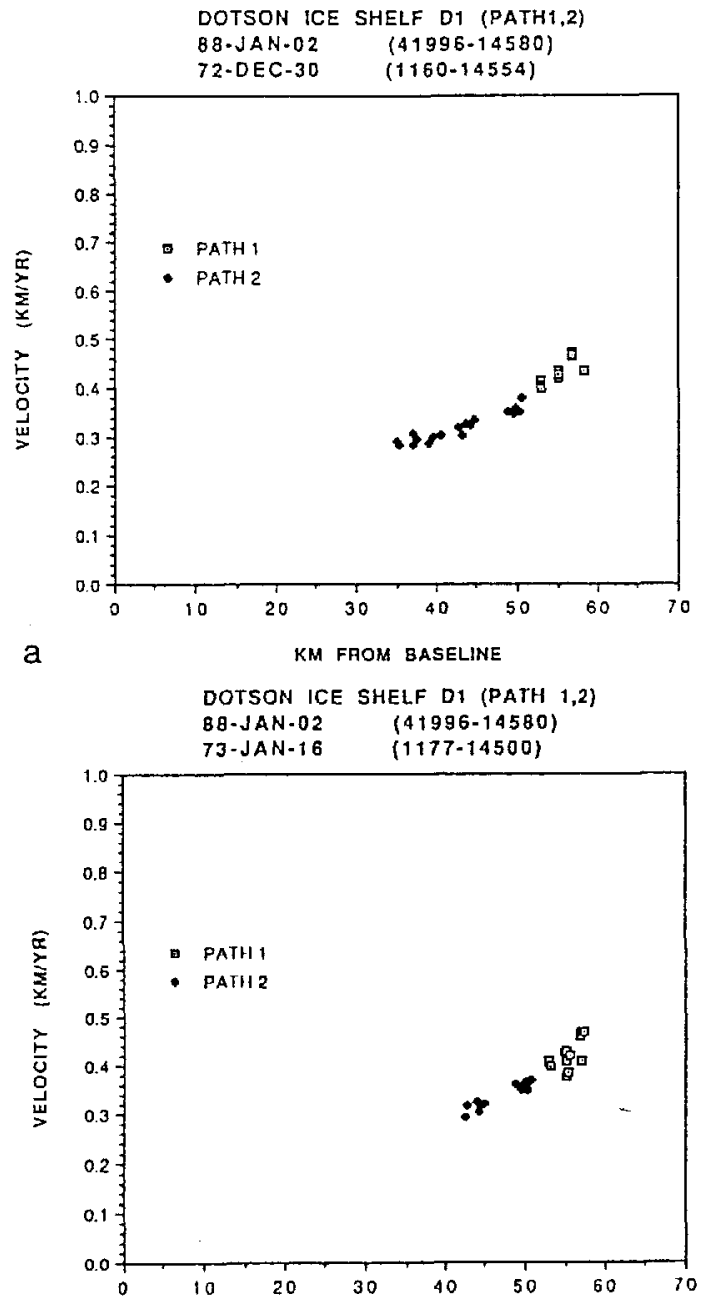

b

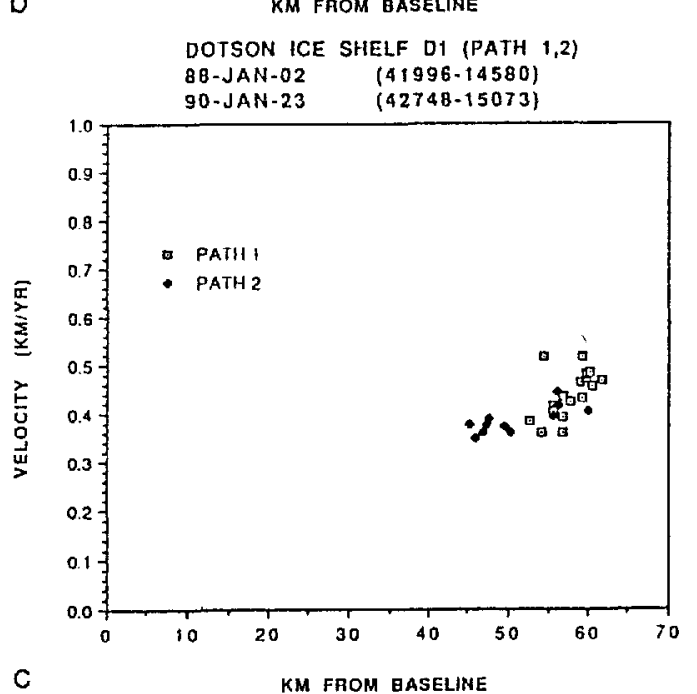

central part of the ice shclf. Thus, the drainage basin for part of the Dotson Ice Shelf is the same as that of Smith Glacier. The western part of the ice shelf drains the Martin Peninsula ice rises (Figs 2, 3 and 4).

The Dotson Ice Shelf velocities were measured in three time intervals: 1972-88 (Fig. 2), 1973-88 (Fig. 3) and 1988-90 Fig. 4). We subdivided the ice shelf into two segments and each segment into two paths.

The average velocitics of Dotson DI (Figs 2, 3, 6a and b; Table 2) are for almost identical time intervals and are indeed very similar. T'he average velocity for the 198890 lime interval (Figs 4 and $6 c$; Table 2) also remained the same. The scatter in the Dotson D) 1, path 1 plots (Fig. 6a, b
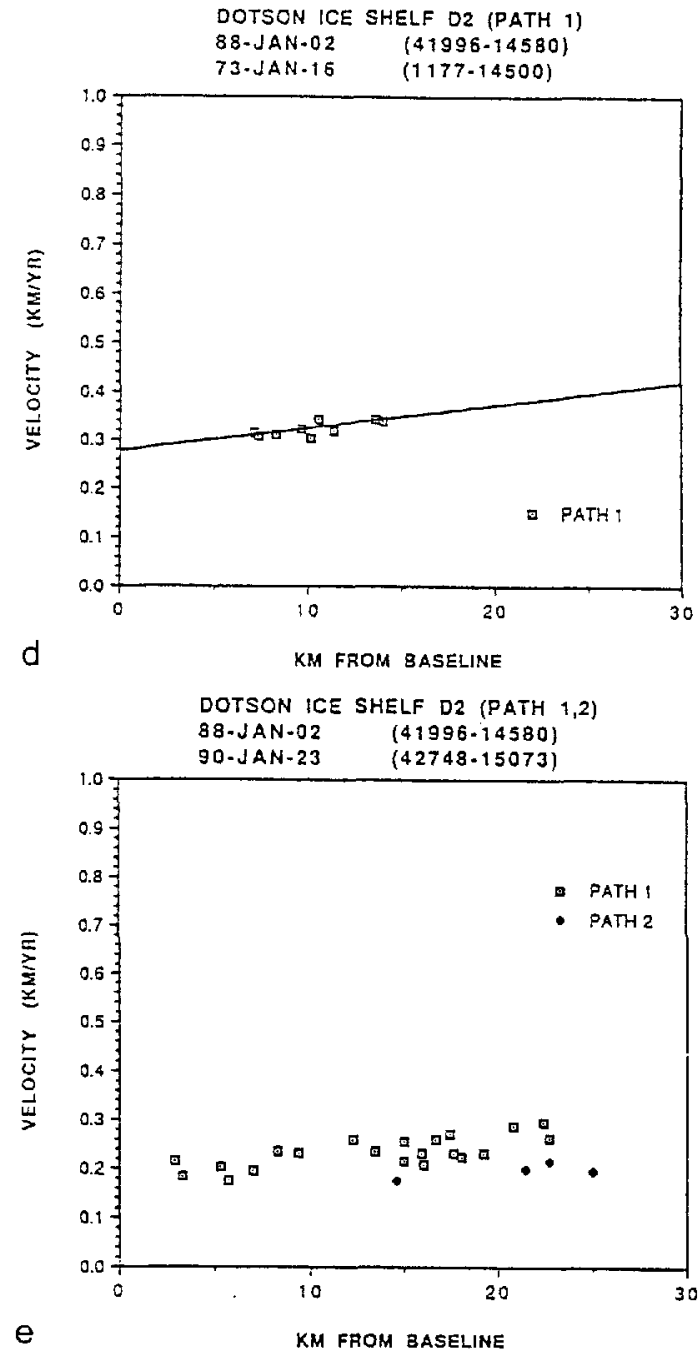

Fig. 6. Average unnual velocity of the Dotson Ice Shelf plotted against distance to base line. a. 15.0 year interval, $1972-88$; b. 15.0year interwal, $197388 ;$ c. 2.1 year interval, 1988-90; d. 15.0year interval, 1973-88 (note change in scale); e. 2.1 year intercal, 1988-90 (note change in scale). and c) probably reflects the width of the path, which covers ncarly half the ice shelf. Therefore, the spread in velocities may represent faster ice movement near the center and slower movement toward the margins of this ice shelf.

The Dotson D2 ice-shelf segment has low velocities, in keeping with icc shelves elsewhere that are not fed by major ice streams (Figs 3, 4, 6d and e; lable 2). The somewhat higher speeds in the earlier image set may be real but they may also reflect the fact that relatively few points were sampled. Also, the distances measurcd on the later set are short $(<0.5 \mathrm{~km})$, which makes our velocity uncertaintics proportionately larger for this data set. The slope on the plotted points is low, indicating little increase 
in velocity toward the terminus of the ice shelf. This observation may reflect the location of this part of the ice shelf in a small bay within Martin Peninsula (so that it is constrained on both sides), as well as the relatively small size of the intake area for this part of the ice shelf.

\section{DISGUSSION}

Our data support the premise that the higher average velocities of the Smith Glacier ice tongue in the 1988-90 time interval reflect a true increase in velocities (Fig. 7a). If the higher velocities were an artifact of our procedure or of the images, similar increases should be noted elscwhere. Yct, even though the same images were used for the Dotson Ice Shelf measurements, no equivalent

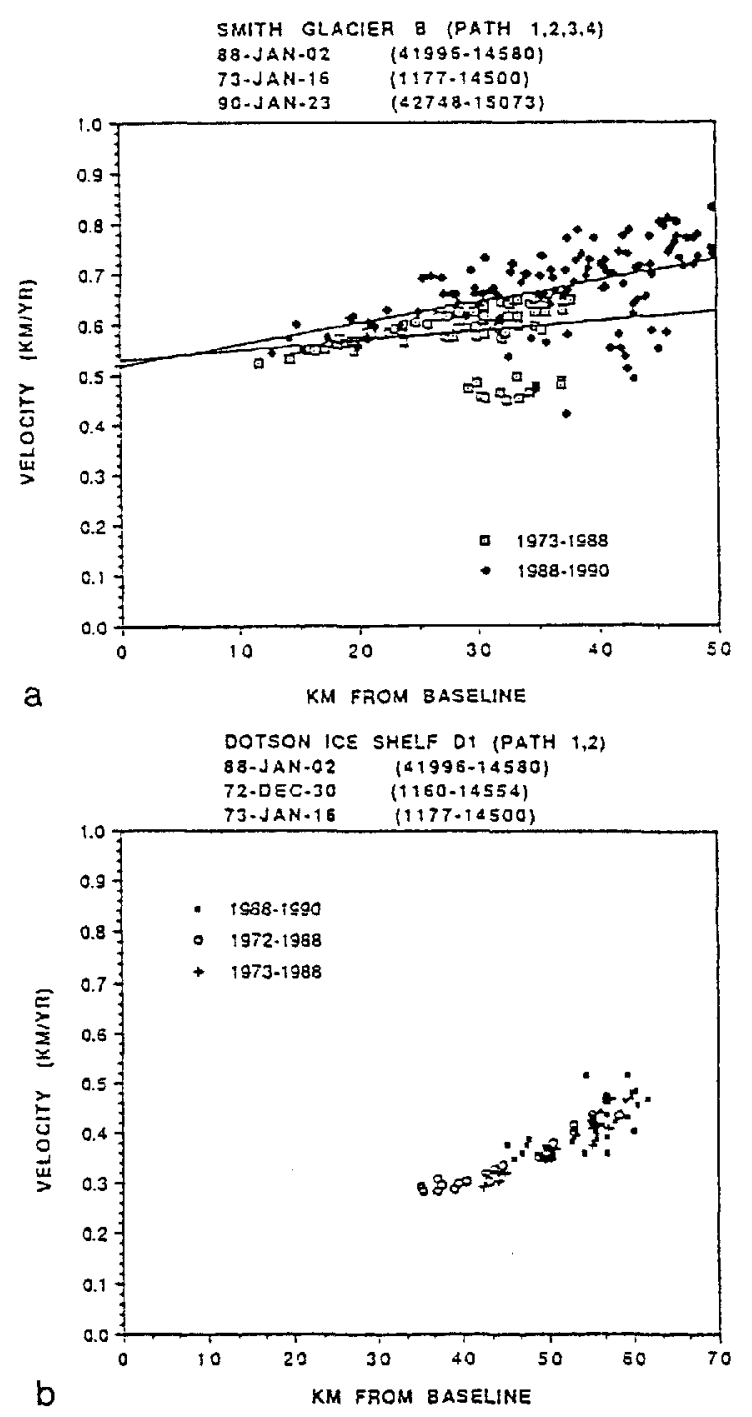

Fig. 7. a. Average annual velocity of paihs $1-3$, segment $B$, on Smith Glacier plotted against distance to base line. Comparison of movement of 1973-88 (15.0 year interval) and 198890 (2.1 year interval). Note the convergence toward the grounding line of the regression lines of the two data sets. b. Average annual velocity of segment $D 1$ on Dotson Ice Shelf plotted against dislance to base line. Comparison of movements of 1988-90 (2.1 year interval), 1972-88 (15.0year interval) and 197388 (15.0year interval). increases were noted there (Fig. 7b). Furthermore, Figure 7a clearly shows a convergence of the velocities toward the base line. This observation suggests that the velocities were similar near the grounding line in both the earlier and later time intervals, reflecting no change in discharge from the ice sheet. On the floating ice tongue, however, the velocities show an increase toward the calving front for the later interval.

What caused this increase in velocities? Figures 2 and 3 , and adjacent Landsat images (Thwaites Glacier area; Ferrigno and others, 1993), show that in 1972 and 1973 the Amundsen Sea in front of the Smith Glacier icetongue terminus and between the Thwaites and Smith Glacicr ice tongues was densely packed with large floating icebergs, whereas in 1990 the area was virtually clear (Fig. 8). By 1984, most of the icebergs were still in the vicinity but a large, rounded iceberg had broken off Smith Glacier. By 1988, most of the icebergs had drifted away, the rounded iceberg had rotated counter-clockwise and drifted out about $15 \mathrm{~km}$ and a second large iceberg of more rectangular shape had broken off the ice tongue. By 1990, the rounded iceberg had moved $60 \mathrm{~km}$ out to sea, away from the 1988 position (Fig. 8). The distance of drift of the rounded iceberg in just 2 years corresponds to that of the Thwaites Glacier iceberg tongue during the same time interval (Ferrigno and others, 1993). Perhaps the rotation and drifting were aided by strong winds that were reported for the general area by Kellogg and Kellogg (1987).

The increase in velocity of the Smith Glacier ice tongue is probably related to this clearing of icebergs in front of the ice tongue. Until 1984, the Smith Glacier ice tongue was buttressed by tightly packed icebergs, possibly welded by multi-year sea ice and wedged between the Thwaites Glacier ice tongue (seen in adjacent Landsat images; in Ferrigno and others, 1993, fig. 2) and pinning points of Bear Peninsula. After 1984, the area apparently began to clear. In contrast to observations on earlier

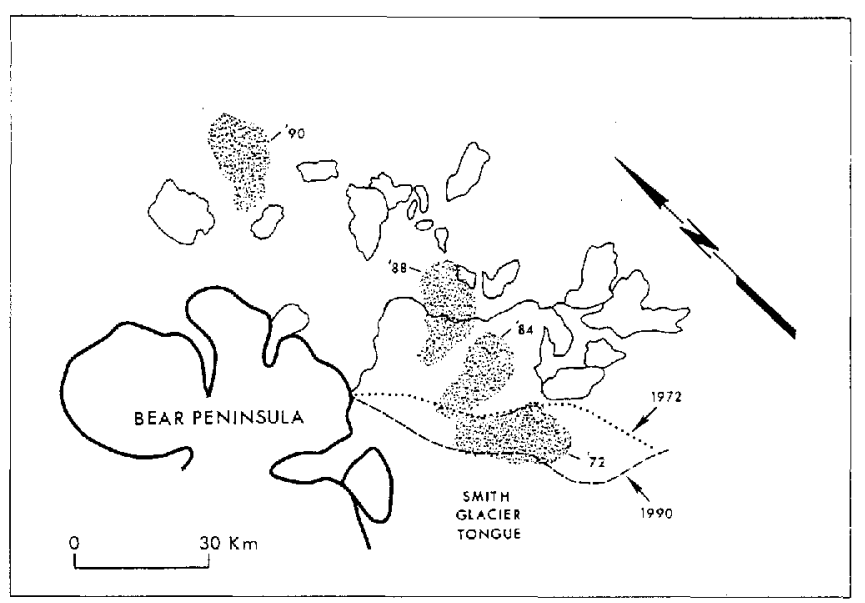

Fig. 8. Sketch map showing position of the Smith Glacier ice-longue terminus in 1972 (dotted line). The thin solid lines enclose icebergs in front of the terminus in 1972. Position of Smith Glacier ice-tongue terminus in 1990 (dashed line). Region in front of the terminus was clear of icebergs in 1990. Stippled iceberg was part of the Smith Glacier ice tongue in 1972 and moved to indicated positions in 1984,1988 and 1990. 
images, in January 1988, open water locally covered by thin sea ice was present next to the Smith Glacier terminus (Figure 4 and adjacent Landsat images; not shown). Sometime after 1984, the ice tongue apparently began to spread, probably through the opening of crevasses, resulting in the apparent increase of velocities detected in the 1988-90 time interval.

'The front of the Smith Glacier ice tongue, and of a small ice tongue between the Smith and Thwaites Glacier ice tongues, receded by about $10 \mathrm{~km}$ between 1984 and 1990. During this time interval, the Thwaites Glacier ice tongue lost about $60 \mathrm{~km}$ of ice due to calving (Ferrigno and others, 1993). Bctwcen 1973 and 1988, the front of the Dotson Ice Shelf receded $57 \mathrm{~km}$. The timing of these calving events may be coincidental. On the other hand, the loss of icebergs and calving of ice tongues is also consistent with a general decrease of shelf ice in the area. Kellogg and others (1985) stated that "it appears that the entire Pine Island Bay region experiences a negative net mass balance, primarily from sublimation". Perhaps we are sceing the last stages of an icc shelf that purportedly filled the entire Pine Island Bay only 100 years ago (Kellogg and Kellogg, 1987). Perhaps, also, we are observing a process similar to the disintegration of the Wordie Ice Shelf on the Antarctic Peninsula (Doake and Vaughan, 1991). There, the disintegration of shelf ice was also accompanied by increased velocities and facilitated by the retreat of the calving front away from pinning points. Doake and Vaughan attributed the disintegration of the Wordie Ice Shelf to increased air temperatures in the region, perhaps coupled with increased ocean temperatures. Ablation and meltwater were supposed to have contributed to the formation of crevasses and rifts, thus facilitating the drifting away of ice blocks.

\section{SUMMARY}

The Dotson Ice Shelf velocities changed little over the time period investigated (1972-90) but calving reduced its front by $5-7 \mathrm{~km}$. In contrast, the Smith Glacier ice tongue increased in velocity by about $0.1 \mathrm{kmyear}^{-1}$, and calving reduced its front by about $10 \mathrm{~km}$. The increase in velocity appears to be confined to the floating part of the glacier below the grounding line. During the mid to late 1980s, the bay in front of the Smith Glacier ice tongue lost partly pinned icebergs that appcarcd to have buttressed the ice tongue. This process may have freed the calving front and permitted the spreading of the ice tongue, resulting in the apparent increase in velocity. The cause of the general loss of ice in this region is unknown but it may be related to changes in wind direction or warming of the air or ocean.

\section{AGKNOWLEDGEMENTS}

We are grateful for helpful reviews by H.H. Kieffer and D. J. Chadwick, and two anonymous reviewers. J. M. Barrett helped in developing computer programs. The rescarch was funded by the U.S. Geological Survey's Global Change and Climate History Program.

\section{REFERENCES}

Borgeson, W. T., R.M. Batson and H.H. Kieffer. 1985. Geometric accuracy of Landsat 4 and Landsat -5 'l'hematic Mapper images. Photogramm. Eng. Remote Sensing, 51 (12), 1893-1898.

Crabtrec, R. D. and C.S.M. Doake. 1982. Pine Island Glacier and its drainagc basin: results from radio-echo sounding. Ann. Glaciol, 3, 65-70.

Doake, C.S.M. and D.G. Vaughan. 1991. Rapid disintegration of the Wordie Ice Shelf in response to atmospheric warming. Nature, 350 6316$), 328-330$.

Drewry, D.J., ed. 1983. Antarcica: geological and geophystal folio. Cambridge, University of Cambridge. Scott Polar Research Institute.

Ferrigno, J. G., B. K. Lucchitta, K. F. Mullins, A. L. Allison, R. J. Allen and W.G. Gould. 1993. Velocity measurements and changes in position of Thwaites Glacier/iceberg tongue from acrial photographs, Landsat images and NOAA AVHRR data. Ann. Glaciol., 17, 239-244.

Hughes, 'T.J. 1981. The weak underbelly of the West Antarctic ice sheet. J. Glaciol., 27(97), 518525.

Kcllogg, T. B. and D. E. Kellogg. 1987. Recent glacial history and rapid ice retrcat in the Amundsen Sea. 7. Geophys. Res., 92(B9), 8859-8864.

Kellogg. T.B., D.E. Kellogg and T.J. Hughes. 1985. Amundsen Sea sediment covering. Antarct. F. U.S., 20(5), 79-81.

Lindstrom, D. and T.J. Hughes. 1984. Downdraw of the Pine Island Bay drainage basins of the West Antarctic ice sheet. Antart. f. L.S., 19 ) $56-58$.

Lindstrom, D. and D. Tyler. 1984. Preliminary results of Pine Island and Thwaitcs Glacier study. Antarcl. F. U.S., 19(5), 53-55.

Lucchitta, B. K., K. F. Mullins, A. L. Allison and J. G. Ferrigno. 1993. Antarctic glacicr-tongue velocities from $I$ andsat images: lirst results. Ann. Glaciol. 17, 356-366.

Swithinbank, C. 1988. Satellite image atlas of glaciers of the world Antarctica. C.S. Geol. Sur. Prof. Pap. 1386-B, 1-138.

U.S. Geological Survey. 1968. Antartic sketch map: Bakulis Coast-Marie Byrd Land. Washington, DC, U.S. Geological Survey.

Welch. R., T. R. Jordan and M. Ehlers. 1985 . Comparative evaluations of the geodetic accuracy and cartographic potential of Landsat-4 and landsat-5 Thematic Mapper image data. Phologramm. Eng. Remote Sensing, 51(9), 1249-1262.

The accuracy of references in the text and in this list is the responsibility of the authors, to whom queries should be addressed. 